\title{
Importância dos fatores de crescimento locais na regulação da foliculogênese ovariana em mamíferos
}

\author{
Importance of local growth factors in the regulation \\ of ovarian folliculogenesis in mammals

\section{Cintia Camurça Fernandes Leitão', Ivina Rocha Brito², Isana Mara Aragão Frota' \& José Roberto Viana Silva'}

\section{RESUMO}

O ovário mamífero é um órgão dinâmico encarregado de proporcionar um ambiente ideal para a produção de hormônios e liberação dos gametas femininos. No ovário, estão contidos milhares de folículos ovarianos, que constituem sua unidade básica estrutural e funcional. A foliculogênese ovariana é um processo complexo que consiste do desenvolvimento de folículos primordiais até o estágio de folículo pré-ovulatório, durante o qual ocorre o crescimento oocitário e intensa proliferação das células da granulosa. Vários fatores de crescimento produzidos pelas células foliculares, frequentemente, atuam modulando os efeitos das gonadotrofinas FSH e LH, controlando, assim, a foliculogênese. Nesta revisão, serão discutidos a localização e os efeitos de vários fatores como o fator de crescimento epidermal (EGF), fatores de crescimento fibroblásticos (FGF), fator de crescimento semelhante à insulina (IGF), fatores de crescimento transformante-ß (TGF-ß) e Kit ligante (KL) no controle do desenvolvimento folicular. Alguns desses fatores de crescimento, como EGF, FGF, IGF, TGF- $\beta$, BMP-2, -4, -6, -7, -15, GDF-9, ativina-A e KL, estimulam o desenvolvimento dos folículos ovarianos, além de estarem envolvidos no controle dos processos de esteroidogênese e atresia folicular. Já outras substâncias, como as inibinas, exercem uma ação inibitória sobre a secreção de gonadotrofinas e controlam, desta forma, a ação do FSH no ovário.

Descritores: foliculogênese, fatores de crescimento, mamíferos.

\section{ABSTRACT}

The mammalian ovary is a dynamic organ that provides an ideal environment for the production of hormones and release of the female gamete. The ovary contains thousands of ovarian follicles which are its basic structural and functional unit. The ovarian folliculogenesis is a complex process that consists of the development of primordial follicles to the stage of preovulatory follicle, occurring oocyte growth and intense proliferation of the granulosa cells during this period. Several growth factors produced by follicular cells often act by modulating the effects of gonadotrophins FSH and LH, controlling thus folliculogenesis. In this review will discuss the localization and in vitro effects of growth factors, such as epidermal growth factor (EGF), fibroblastic growth factor (FGF), insulin-like growth factor (IGF) transforming growth factor- $\beta$ (TGF- $\beta$ ) and Kit ligand (KL) in the control of follicular development. Some of these growth factors, such as EGF, FGF, IGF, TGF-ß, BMP-2, -4, $-6,-7,-15$, GDF-9, activin-A and KL stimulate the development of ovarian follicles and are involved in the control of steroidogenesis and follicular atresia. On the other hand, a few factors, like inhibin, exert an inhibitory action on the secretion of gonadotropins and control the effect of FSH in the ovary.

Keywords: folliculogenesis, growth factors, mammals. 


\title{
I. INTRODUÇÃO
}

\section{FATORES DE CRESCIMENTO PERTENCENTES À FAMÍLIA EGF}

\section{FATORES DE CRESCIMENTO PERTENCENTES À FAMÍLIA FGF}

\section{IGF E PROTEÍNAS DE LIGAÇÃo DE IGF (IGFBP) \\ V. FATORES DE CRESCIMENTO PERTENCENTES À FAMÍLIA TGF-ß}

\author{
VI. KIT LIGANTE (KL)
}

\section{CONSIDERAÇÕES FINAIS}

\section{INTRODUÇÃO}

O ovário mamífero é um órgão composto por vários tipos celulares diferenciados e pode ser dividido em duas regiões: uma medular, que, na maioria das espécies, consiste na porção interna do ovário e é constituída por tecido conjuntivo, nervos, artérias e veias; e uma região cortical, que contém corpos lúteos, albicans e folículos ovarianos em diferentes estágios de desenvolvimento. Além dos nutrientes e hormônios provenientes da corrente sanguínea, fatores produzidos pelos diferentes tipos celulares contribuem para a formação de um sistema bastante complexo que regula as funções do ovário, ou seja, a produção de gametas e hormônios [16].

Ao processo de formação, crescimento e maturação dos folículos ovarianos dá-se o nome de foliculogênese. Este processo inicia-se ainda na vida pré-natal, na maioria das espécies, com a formação do folículo primordial e culmina com o estágio de folículo pré-ovulatório [71]. Os folículos ovarianos são classificados de acordo com o grau de evolução em préantrais, compreendendo os primordiais, primários e secundários, e em antrais, caracterizados pela presença de uma área preenchida por fluido folicular, em que, a partir de então, passam a ser subclassificados como terciários e pré-ovulatórios. Os folículos pré-antrais representam cerca de 90 a $95 \%$ de toda a população folicular [18].

O folículo primordial é constituído por um oócito imaturo, circundado por uma simples camada de células da pré-granulosa de formato pavimentoso [28]. Quando o oócito é circundado por uma camada completa de células da granulosa de formato cúbico, o folículo é classificado como primário. A multiplicação das células da granulosa dos folículos primários leva à formação de várias camadas dessas células ao redor do oócito, formando o folículo secundário. Com a intensa proliferação das células da granulosa, uma área preenchida por fluido folicular é identificada na camada granulosa e, a partir de então, os folículos passam a ser classificados como antrais. A partir desse estágio, o diâmetro folicular aumenta acentuadamente, devido ao crescimento do oócito, multiplicação das células da granulosa, da teca e aumento da cavidade antral. No último estágio do desenvolvimento folicular, o folículo pré-ovulatório é caracterizado por um oócito circundado por células da granulosa especializadas que são denominadas células do cúmulus [46].

O processo de crescimento e a maturação folicular são controlados por uma perfeita interação entre fatores endócrinos, autócrinos e parácrinos. Diversos estudos têm comprovado que os fatores de crescimento, como EGF, FGF, IGF, TGF-ß e KL são de grande importância durante este processo, os quais podem atuar de diferentes formas sobre todas as fases da foliculogênese [71]. Estes fatores de crescimento, que são produzidos pelo oócito, células da granulosa e células da teca, frequentemente atuam modulando os efeitos de FSH e LH. Desta forma, a foliculogênese pode ser desregulada quando um determinado fator está ausente [15].

A presente revisão tem como objetivo apresentar e discutir a localização e os principais efeitos biológicos dos fatores de crescimento pertencentes à família EGF, FGF e TGF- $\beta$, bem como IGF e KL em ovários mamíferos.

\section{FATORES DE CRESCIMENTO PERTENCENTES À FAMÍLIA EGF}

Os fatores de crescimento pertencentes à família EGF que participam do controle da foliculogênese são: o próprio EGF, o fator de crescimento transformante- $\alpha$ 
(TGF- $\alpha$ ), o fator ligante de heparina semelhante ao EGF (HB-EGF), a anfiregulina, a betacelulina e a epiregulina. O EGF é uma proteína de $6 \mathrm{kDa}$ que tem sido demonstrada no oócito e em células da granulosa de folículos pré-antrais e antrais suínos, enquanto que o RNA mensageiro para EGF tem sido demonstrado, nesta espécie, em oócitos e células da granulosa de folículos antrais [64]. Em caprinos, estudos demonstraram que o EGF é expresso em todos os estágios de desenvolvimento folicular, no corpo lúteo e no epitélio da superfície ovariana [62].

A ação do EGF nos folículos ovarianos é mediada por um receptor presente na membrana celular, ErbB1, que pertence à superfamília ErbB. Este receptor de EGF (EGF-R) funciona como receptor de, pelo menos, seis diferentes membros da família EGF: o próprio EGF, TGF- $\alpha$, HB-EGF, anfiregulina, betacelulina e epiregulina [53]. O RNA mensageiro e a proteína para o EGF-R têm sido identificados em oócitos e células da granulosa de folículos pré-antrais e antrais de caprinos [62], suínos [64] e humanos [49].

Todas essas evidências sugerem que o EGF exerce um papel central no controle da atividade ovariana em mamíferos. Realmente, em caprinos, estudos demonstraram que o EGF estimula o aumento do diâmetro folicular, através da promoção do crescimento do oócito [63] e do número de células foliculares [51]. O EGF também reduz os níveis de atresia em folículos pré-antrais bovinos cultivados in vitro [74]. Além disso, o EGF tem estimulado a maturação oocitária em folículos antrais ovinos [23], a expansão das células do cúmulus em camundongos [42] e a produção de estrógeno em humanos [37]. Por outro lado, experimentos in vivo sugerem um possível papel do EGF na indução de atresia [40]. No entanto, o efeito do EGF na indução de atresia em condições fisiológicas é questionável, pois um efeito antiapoptótico do EGF tem sido demonstrado durante o cultivo de células da granulosa de folículos pré-ovulatórios de ratas [69]. Além disso, o EGF pode atuar localmente no ovário controlando a ação de FSH e LH, pois alguns estudos mostraram que o EGF inibe a produção de receptores de LH [26] e aumenta a expressão de receptores de FSH [34].

Os outros fatores de crescimento pertencentes à família EGF que têm ação direta no ovário são o TGF- $\alpha$, o HB-EGF, a anfiregulina, a betacelulina e a epiregulina. A expressão de TGF- $\alpha$ tem sido demonstrada em óocitos, cúmulus, células da granulosa e da teca em todos os estágios do desenvolvimento folicular em humanos [52]. In vitro, o TGF- $\alpha$ tem estimulado a proliferação de células da granulosa e da teca em bovinos [65]. O TGF- $\alpha$ também atua modulando a expressão de receptores de FSH [19], pois esse fator tem inibido a ação estimulatória do FSH sobre a atividade da enzima aromatase [1]. Com relação aos outros membros da família EGF, o HB-EGF tem sido recentemente demonstrado em células da granulosa de folículos pré-antrais e antrais, mas está ausente em folículos pré-ovulatórios. Isto sugere que o HB-EGF pode ser um fator mitogênico para as células da granulosa e que a redução da sua expressão pode ser necessária para a maturação folicular [44]. A anfiregulina, a beta-celulina e a epiregulina foram também demonstradas em células da granulosa de folículos pré-ovulatórios. A expressão desses fatores é estimulada pelo LH, e, in vitro, anfiregulina, betacelulina e epiregulina estimulam a expansão das células do cúmulus e a maturação ooci-tária, sugerindo que eles funcionam como mediadores parácrinos que propagam a ação do LH em folículos pré-ovulatórios [45]. Ainda, no cultivo de células da granulosa humanas luteinizadas, anfiregulina e epiregulina aumentaram a produção de progesterona [2].

\section{FATORES DE CRESCIMENTO PERTENCENTES À FAMÍLIA FGF}

O grupo de fatores de crescimento fibroblásticos (FGF) é composto por pelo menos 20 membros estruturalmente relacionados [48]. Três fatores desse grupo são conhecidos por exercerem importantes funções no controle da foliculogênese (FGF-1, FGF-2 e FGF-7) e, recentemente, sugeriu-se que FGF-8 e -10 possam também estar envolvidos neste processo em bovinos [7]. Os FGF-1 e -7 são expressos em células da granulosa e da teca de folículos antrais [4]. Em bovinos, o RNAm para FGF-7 foi evidenciado em células da teca, mas não em células da granulosa e oócito [7], enquanto que o FGF-2 tem sido demonstrado em oócitos de folículos primordiais e primários e também em células da granulosa de folículos secundários e antrais [72]. Em humanos, a proteína FGF-2 foi detectada em células da granulosa de folículos primários e secundários [50] e em oócitos de todos os estágios de desenvolvimento [3]. Em bovinos, o RNAm para FGF-10 foi detectado em células da teca e oócitos de folículos primordiais, primários e secundários, enquanto a presença da proteína foi demonstrada em oócitos de folículos préantrais e antrais, bem como em células da teca e granulosa de folículos antrais [7]. Já o RNAm para FGF-8 
foi detectado em oócitos, células da granulosa e da teca de folículos isolados [8]. Existem vários tipos de receptores de FGF, entre eles estão o FGFR-1, -2, -2B, -3, -3C e -4 , que têm sido demonstrados em folículos ovarianos [4]. A expressão dos receptores FGFR-2, FGFR-3 e FGFR-4 foi localizada em oócitos humanos de todas as classes foliculares. Em bovinos, FGFR-3C foi expresso em células da granulosa de folículos saudáveis, tendo sua expressão aumentada com o desenvolvimento folicular. O RNAm para FGFR-3C foi detectado em células da granulosa e da teca [8]. Já o FGFR-2B, receptor para FGF-7 e -10, é expresso em células da granulosa de bovinos [4]. O FGF-2 exerce seus efeitos biológicos por meio da ligação com dois tipos de receptores, ou seja, FGFR-1IIIC e FGFR-2IIIC [43]. Os receptores para FGF-2 têm sido identificados em folículos ovarianos e corpo lúteo e, dessa forma, o FGF-2 tem atuado como um potente regulador das funções ovarianas em diferentes espécies, promovendo início do crescimento de folículos primordiais e primários [41], bem como a esteroidogênese e a diferenciação em folículos antrais bovinos [73]. Além disso, o FGF-2 tem ação antiapoptótica e atua na diferenciação das células da granulosa em células luteínicas durante o processo de luteinização [32]. O FGF-7 também exerce importantes funções na regulação das atividades de células da granulosa [47]. Quando testado em caprinos, o FGF-2 (50 ng/mL) promoveu um aumento significativo dos folículos em desenvolvimento e manutenção da viabilidade folicular durante 5 dias de cultivo [36].

\section{IGF E PROTEÍNAS DE LIGAÇÃO DE IGF (IGFBP)}

Diversas evidências têm mostrado que um sistema formado pelos fatores de crescimento semelhantes à insulina (IGF) e às proteínas de ligação de IGF (IGFBP) exerce importantes funções no controle do desenvolvimento folicular e atresia em animais domésticos [38]. Na maioria das espécies mamíferas, o IGF aumenta a proliferação de células da granulosa, a esteroidogênese e o crescimento do oócito [57]. O sistema IGF é composto por diferentes elementos, ou seja, IGF-1 e IGF-2, dois tipos de receptores (IGFR-1 e IGFR-2) e seis IGFBP (IGFBP-1, -2, -3, -4, -5 e -6). O IGFR-1 funciona como receptor para os dois tipos de IGF, enquanto que o IGFR-2 tem maior afinidade para IGF-2 [30]. Ambos receptores de IGF estão presentes em células da granulosa de folículos primários, secundários e antrais [39].
As IGFBPs podem ser encontradas nos fluidos biológicos e atuam inibindo ou potencializando a ação dos dois tipos de IGFs nas células-alvo. Durante o crescimento de pequenos folículos antrais para o estágio de folículos pré-ovulatórios, observa-se uma redução progressiva dos níveis de IGFBP, devido principalmente a alterações nos processos de síntese e/ou degradação [38]. Por outro lado, em folículos que estão sofrendo atresia, os níveis de IGFBPs são altos, principalmente devido a uma redução no processo de degradação [5]. Com o aumento dos níveis de IGFBPs ocorre uma redução da disponibilidade de IGF livre no ambiente folicular. Após a ovulação, evidências sugerem que o sistema IGF pode estar envolvido na manutenção e na regressão do corpo lúteo. Desta forma, foi demonstrado um efeito regulatório do LH sobre a expressão do RNAm que codifica o IGF-1 em corpo lúteo de ovinos [24].

Em caprinos, a proteína e o RNAm para IGF-1 são expressos em todas as categorias foliculares, mas as células da granulosa e da teca de folículos antrais são as principais responsáveis pela produção de IGF-1 nesta categoria folicular [56]. A adição de IGF-1 (100 ng/mL) ao meio de cultivo mantém a sobrevivência dos oócitos e estimula o crescimento in vitro de folículos pré-antrais caprinos. Ainda nesta espécie, o IGF-1 estimula o crescimento de oócitos de folículos pré-antrais, tendo sua ação reforçada pelo EGF [79]. Em equinos, o aumento dos níveis de IGF-1 está associado ao aumento da esteroidogênese em folículos em desenvolvimento [67]. Além disso, pesquisas demonstraram que a adição de IGF-1 ao meio de cultivo de grandes folículos secundários promove o aumento da incidência de dominância folicular e ovulação [20]. Ainda, a adição de IGF-1 ao meio de maturação in vitro promove a capacidade de desenvolvimento de oócitos e aumenta a produção de blastocistos após fertilização in vitro em murinos [13].

No tocante ao IGF-2, este é expresso nas células da granulosa de folículos saudáveis e atrésicos [80]. Foi demonstrado que IGF-2 aumenta a síntese de DNA em células da granulosa após o cultivo in vitro de folículos pré-antrais caprinos [51]. Em ovários ovinos, o IGF-2 é apontado como o principal componente do sistema IGF, apresentando grande importância para o crescimento de pequenos folículos antrais nesta espécie [25].

\section{FATORES DE CRESCIMENTO PERTENCENTES À FAMÍLIA TGF- ß}

A família de fatores de crescimento TGF- $\beta$ é composta por mais de 40 membros [10], sendo que os 
principais fatores que exercem funções no ovário são as proteínas morfogenéticas ósseas dos tipos 2 (BMP-2), 4 (BMP-4), 6 (BMP-6), 7 (BMP-7), 15 (BMP-15), o fator de crescimento e diferenciação-9 (GDF-9), a ativina-A, a inibina e o próprio fator de crescimento transformante- $\beta$ (TGF-B).

A maioria dos membros da superfamília TGF- $\beta$ exerce seus efeitos sobre as células-alvo através da formação de um complexo com dois tipos de receptores localizados na superfície das células, designados de Tipo-I e Tipo-II [10]. Em mamíferos, já foram identificados vários receptores do tipo-I [BMPR-IA (ALK3), BMPR-IB (ALK6), ActR-IA (ALK2), ActR-IB (ALK4), TßR-I (ALK5)], e do tipo-II [BMPR-II, ActR-IIA, ActR-IIB, TßR-II]. Geralmente, ligações entre membros da família TGF- $\beta$ e ativina ocorrem através de receptores tipo II, enquanto os membros da família BMP têm alta afinidade por receptores tipo I [12]. Também, um terceiro tipo de receptor, o TGF-ßRIII, tem sido demonstrado. Este pode atuar facilitando a ligação do TGF-32 ao receptor tipo II e, ainda, facilita a associação da inibina com o receptor tipo II de ativina, antagonizando, assim, as ações da ativina [22] e de uma série de BMPs [77].

A expressão de BMPR-II, BMPR-IA (ALK3) e BMPR-IB (ALK6) foi demonstrada em folículos primordiais, primários e secundários, bem como em oócitos, células da granulosa e da teca de folículos antrais caprinos. Os RNAs mensageiros para BMPR-IA (ALK3), BMPR-IB (ALK6) e BMPR-II foram detectados nos folículos primordiais, primários, secundários, bem como no oócito e células da granulosa de folículos antrais [59]. Já os receptores para TGF- $\beta$, TßRI ou ALK5 e TßRII, são aparentemente expressos em muitos tipos celulares.

No que se refere às BMPs, a proteína BMP-2 foi demonstrada em células da teca e em oócitos de folículos antrais bovinos [17]. Já foi descrito que este fator promove diferenciação [66] e aumenta a secreção de inibina-B em células da granulosa cultivadas in vitro [29]. O RNAm para BMP-4 e a sua proteína são expressos em células da granulosa e da teca de bovinos [21], bem como em oócitos de folículos antrais [17]. Em estudos in vivo com camundongos, evidenciouse o envolvimento da BMP-4 na transição de folículos primordiais para o estágio de folículos primários [68]. A BMP-6 é produzida por oócitos, assim como por células da granulosa e da teca em bovinos [21] e ovinos
[31]. Em caprinos, a proteína para BMP-6 é expressa em oócitos de folículos ovarianos em todos os estágios de desenvolvimento [55]. Essa proteína atua no ovário estimulando a proliferação das células da granulosa, promovendo viabilidade celular e aumentando a produção de inibina-A, ativina-A e folistatina em células da granulosa de bovinos [21].

Estudos anteriores demonstraram que a BMP-7 é produzida pelas células da teca de folículos secundários e antrais [54]. No cultivo in vitro de folículos, BMP-7 promoveu a ativação e o crescimento de folículos primordiais [33]. Já a proteína BMP-15 foi encontrada em oócitos de todos os tipos de folículos e células da granulosa de folículos primários, secundários e antrais caprinos. O RNAm para BMP-15 foi detectado em folículos primordiais, primários e secundários, bem como no oócito e em células da granulosa de folículos antrais [59]. Estudos in vitro têm demonstrado que esta proteína promove a proliferação das células da granulosa e estimula o desenvolvimento de folículos primordiais e primários [31].

O GDF-9 é um fator secretado pelo oócito [10] e atua estimulando a manutenção da viabilidade folicular e a proliferação de células da granulosa em humanos [27]. Em caprinos, o RNAm para GDF-9 foi localizado no oócito e nas células da granulosa, assim como os seus receptores estavam expressos em todas as categorias foliculares [59]. A expressão da proteína e do RNAm para ativina-A e seus receptores foi demonstrada em oócito e células da granulosa de folículos pré-antrais e antrais em caprinos [60]. No cultivo in vitro, a adição de ativina-A estimulou a ativação, o crescimento e aumentou a percentagem de folículos pré-antrais caprinos morfologicamente normais [58]. Com relação às inibinas, estas apresentam uma ação inibitória sobre a secreção de FSH pela pituitária [35]. A inibina B é principalmente produzida pelas células da granulosa de folículos antrais pequenos [76], enquanto que a inibina A é produzida por folículos dominantes e corpo lúteo [75].

Em mamíferos, a subfamília TGF- $\beta$ é composta por três isoformas, denominadas TGF- 31 , TGF- $32 \mathrm{e}$ TGF-B3. O RNAm para TGF-ß e a proteína são encontrados nas células da teca e da granulosa, bem como em oócitos [6]. O TGF-ß pode estimular a expressão de receptores para FSH, a produção de inibina e de progesterona e a indução de receptores para $\mathrm{LH}$, além de amplificar a atividade da aromatase sobre o FSH [14]. 


\section{KIT LIGANTE (KL)}

O Kit ligante (KL) é um fator de crescimento produzido localmente que desempenha um importante papel no controle da função ovariana [78]. Em ovinos, o KL tem sido demonstrado em células da granulosa de folículos pré-antrais e antrais [70], enquanto o receptor para KL, c-Kit, é expresso em oócitos de folículos em todos os estágios de desenvolvimento [11]. Em humanos, o KL é encontrado em oócitos de folículos pré-antrais e em células da granulosa de folículos pré-antrais e antrais [9]. O receptor c-Kit também está presente nas células da teca de folículos antrais em ovinos [11]. Em caprinos, a proteína e o RNAm para KL foram encontrados em folículos em todos os estágios de desenvolvimento, ou seja, primordial, primário, secundário, pequenos e grandes folículos antrais, bem como no corpo lúteo, superfície do epitélio e tecido medular ovariano. A proteína KL foi demonstrada em células da granulosa de folículos a partir do estágio primordial. Já o RNAm foi detectado em células da granulosa isoladas de folículos antrais. O RNAm para o receptor c-Kit foi expresso em todos os compartimentos de folículos antrais. A proteína c-Kit foi predominantemente encontrada em oócitos de folículos em todos os estágios de desenvolvimento, em células da teca de folículos antrais, bem como no corpo lúteo, superfície do epitélio e tecido medular ovariano [61]. Em roedores, KL tem várias funções, incluindo a promoção do crescimento de oócitos durante as fases iniciais de desenvolvimento folicular, a ativação de folículos primordiais e a sobrevivência folicular [28]. Em mamíferos, KL e c-Kit desempenham um importante papel na ativação de folículos primordiais, recrutamento das células da teca, formação de antro e maturação meiótica [28]. Em humanos, o bloqueio do receptor c-kit induziu à atresia folicular [9].

\section{CONSIDERAÇÕES FINAIS}

Nesta revisão de bibliografia, evidenciaram-se as ações diretas e/ou indiretas de vários fatores de crescimento no controle da foliculogênese, atuando na ativação folicular, bem como estimulando a maturação oocitária, a expansão das células do cúmulus, a proliferação das células da granulosa/teca e a produção de estrógeno. Estes fatores de crescimento podem agir isoladamente ou combinados e até mesmo modular o efeito de hormônios sobre o desenvolvimento de folículos ovarianos. Desta forma, o estudo desses fatores de crescimento poderá contribuir para uma melhor compreensão dos eventos que levam à maturação folicular e permitem a competência oocitária, possibilitando, assim, a obtenção de oócitos fertilizáveis que poderão ser utilizados em diferentes biotécnicas de reprodução animal.

\section{REFERÊNCIAS}

1 Adashi E.Y., Resnick C.E. \& Twardzik D.R. 1987. Transforming growth factor-alpha attenuates the acquisition of aromatase activity by cultured rat granulosa cells. Journal of Cellular Biochemistry. 33: 1-13.

2 Ben-Ami I., Armon L., Freimann S., Strassburger D., Ron-El R. \& Amsterdam A. 2009. EGF-like growth factors as LH mediators in the human corpus luteum. Human Reproduction. 24: 176-184.

3 Ben-Haroush A., Abir R., Ao A., Jin S., Kesler-Icekson G., Feldberg D. \& Fisch B. 2005. Expression of basic fibroblast growth factor and its receptors in human ovarian follicles from adults and fetuses. Fertility and Sterility. 84: 1257-1268.

4 Berisha B., Sinowatz F. \& Schams D. 2004. Expression and localization of fibroblast growth factor (FGF) family members during the final growth of bovine ovarian follicles. Molecular Reproduction and Development. 67: 162-171.

5 Besnard N., Pisselet C., Monniaux D. \& Monget P. 1997. Proteolytic activity degrading insulin-like growth factor-binding protein-2, $-3,-4$, and -5 in healthy growing and atretic follicles in the pig ovary. Biology of Reproduction. 56: 1050-1058.

6 Bristol S.K. \& Woodruff T.K. 2004. Follicle-restricted compartmentalization of transforming growth factor beta superfamily ligands in the feline ovary. Biology of Reproduction. 70: 846-859.

7 Buratini Jr. J., Pinto M.G.L., Castilho A.C., Amorim R.L., Giometti I.C., Portela V.M., Nicola E.S. \& Price C.A. 2007. Expression and function of fibroblast growth factor 10 and its receptor, fibroblast growth factor receptor $2 \mathrm{~B}$, in bovine follicles. Biology of Reproduction. 77: 743-750.

8 Buratini Jr. J., Teixeira A.B., Costa I.B., Glapinski V.F., Pinto M.G.L., Giometti I.C., Barros C.M., Cao M., Nicola E.S. \& Price C.A. 2005. Expression of fibroblast growth factor-8 and regulation of cognate receptors, fibroblast growth factor receptor-3c and -4, in bovine antral follicles. Reproduction. 130: 343-350. 
9 Carlsson I.B., Laitinen M.P.E., Scott J.E., Louhio H., Velentzis L., Tuuri T., Aaltonen J., Ritvos O., Winston R.M.L. \& Hovatta O. 2006. Kit ligant and c-Kit are expressed during early human ovarian follicular development and their interaction is required for the survival of follicles in long-term culture. Reproduction. 131: 641-649.

10 Chang H., Brown C.W. \& Matzuk M.M. 2002. Genetic analysis of the mammalian transforming growth factor-beta superfamily. Endocrine Reviews. 23: 787-823.

11 Clark D.E., Tisdall D.J., Fidler A.E. \& McNatty K.P. 1996. Localization of mRNA encoding c-kit during the initiation of folliculogenesis in ovine fetal ovaries. Journal of Reproduction and Fertility.106: 329-335.

12 de Caestecker M. 2004. The transforming growth factor-beta superfamily of receptors. Cytokine \& Growth Factor Reviews. 15: $1-11$.

13 Demeestere I., Gervy C., Centner J., Devreker F., Englert Y. \& Delbaere A. 2004. Effect of insulin-like growth factor-I during preantral follicular culture on steroidogenesis, in vitro oocyte maturation, and embryo development in mice. Biology of Reproduction. 70: 1664-1669.

14 Dunkel L., Tilly J.L., Shikone T., Nishimori K. \& Hsueh A.J. 1994. Follicle stimulating hormone receptor expression in the rat ovary: increases during prepubertal development and regulation by the opposing actions of transforming growth factors beta and alpha. Biology of Reproduction. 50: 940-948.

15 Eppig J.J. 2001. Oocyte control of ovarian follicular development and function in mammals. Reproduction. 122: 829-838.

16 Erickson G.F. \& Shimasaki S. 2003. The spatiotemporal expression pattern of the bone morphogenetic protein family in rat ovary cell types during the estrous cycle. Reproductive Biology and Endocrinology. 1: 9.

17 Fatehi A.N., van den Hurk R., Colenbrander B., Daemen A.J., van Tol H.T., Monteiro R.M., Roelen B.A. \& Bevers M.M. 2005. Expression of bone morphogenetic protein 2 (BMP-2), 4 (BMP-4) and BMP receptors in the bovine ovary but absence of effects of BMP-2 and BMP-4 during IVM on bovine oocyte nuclear maturation and subsequent embryo development. Theriogenology. 63: 872-889.

18 Figueiredo J.R., Rodrigues A.P.R., Amorim C.A. \& Silva J.R.V. 2008. Manipulação de oócitos inclusos em folículos ovarianos pré-antrais. In: Biotécnicas aplicadas à reprodução animal. 2.ed. São Paulo: Roca, pp. 303-327.

19 Findlay J.K. \& Drummond A.E. 1999. Regulation of the FSH Receptor in the Ovary. Trends in Endocrinology and Metabolism. 10: 183-188.

20 Ginther O.J., Gastal E.L., Gastal M.O. \& Beg M.A. 2008. Intrafollicular effect of IGF1 on development of follicle dominance in mares. Animal Reproduction Science. 105: 417-423.

21 Glister C., Kemp C.F. \& Knight P.G. 2004. Bone morphogenetic protein (BMP) ligands and receptors in bovine ovarian follicle cells: actions of BMP-4, -6 and -7 on granulosa cells and differential modulation of Smad-1 phosphorylation by follistatin. Reproduction. 127: 239-254.

22 Gray P.C., Bilezikjian L.M. \& Vale W. 2002. Antagonism of activin by inhibin and inhibin receptors: a functional role for B glycan. Molecular and Cellular Endocrinology. 188: 254-260.

23 Guler A., Poulin N., Mermillod P., Terqui M. \& Cognie Y. 2000. Effect of growth factors, EGF and IGF-I, and estradiol on in vitro maturation of sheep oocytes. Theriogenology. 54: 209-218.

24 Hastie P.M. \& Haresign W. 2006. A role for LH in the regulation of expression of mRNAs encoding components of the insulin-like growth factor (IGF) system in the ovine corpus luteum. Animal Reproduction Science. 96: $196-209$.

25 Hastie P.M. \& Haresign W. 2006. Expression of mRNAs encoding insulin-like growth factor (IGF) ligands, IGF receptors and IGF binding proteins during follicular growth and atresia in the ovine ovary throughout the oestrous cycle. Animal Reproduction Science. 92: 284-299.

26 Hattori M.A., Yoshino E., Shinohara Y., Horiuchi R. \& Kojima I. 1995. A novel action of epidermal growth factor in rat granulosa cells: its potentiation of gonadotrophin action. Journal of Molecular Endocrinology. 15: $283-291$.

27 Hreinsson J.G., Scott J.E., Rasmussen C., Swahn M.L., Hsueh A.L.W. \& Hovatta O. 2002. Growth differentiation factor9 promotes the growth, development, and survival of human ovarian follicles in organ culture. Journal of Clinical Endocrinology \& Metabolism. 87: 316-321.

28 Hutt K.J., Mclaughlin E.A. \& Holland M.K. 2006. KIT/KIT Ligand in mammalian oogenesis and folliculogenesis: roles in rabbit and murine ovarian follicle activation and oocyte growth. Biology of Reproduction. 75: 421-433.

29 Jaatinen R., Bondestam J., Raivio T., Hilden K., Dunkel L., Groome N. \& Ritvos O. 2002. Activation of the bone morphogenetic protein signaling pathway induces inhibin beta (B) - subunit mRNA and secreted inhibin B levels in cultured human granulosa-luteal cells. Journal of Clinical Endocrinology \& Metabolism. 87: 1254-1261. 
30 Jones J.I. \& Clemmons D.R. 1995. Insulin-like growth factors and their binding proteins: biological actions. Endocrine Reviews. 16: 3-34.

31 Juengel J.L. \& McNatty K.P. 2005. The role of proteins of the transforming growth factor-beta superfamily in the intraovarian regulation of follicular development. Human Reproduction Update. 11: 143-160.

32 Lavranos T.C., Rodgers H.F., Bertoncello I. \& Rodgers R.J. 1994. Anchorage-independent culture of bovine granulosa cells: the effects of basic fibroblast growth factor and dibutyryl cAMP on cell division and differentiation. Experimental Cell Research. 211: 245-251.

33 Lee W.S., Otsuka F., Moore R.K. \& Shimasaki S. 2001. Effect of bone morphogenetic protein-7 on folliculogenesis and ovulation in the rat. Biology of Reproduction. 65: 994-999.

34 Luciano A.M., Pappalardo A., Ray C. \& Peluso J.J. 1994. Epidermal growth factor inhibits large granulosa cell apoptosis by stimulating progesterone synthesis and regulating the distribution of intracellular free calcium. Biology of Reproduction. 51: 646-654.

35 Magoffin D.A. \& Jakimiuk A.J. 1997. Inhibin A, inhibin B and activin A in the follicular fluid of regularly cycling women. Human Reproduction. 12: 1714-1719.

36 Matos M.H.T., van den Hurk R., Lima-Verde I.B., Luque M.C.A., Santos K.D.B., Martins F.S., Báo S.N., Lucci C.M. \& Figueiredo J.R. 2006. Effects of fibroblast growth factor- 2 on the in vitro culture of caprine preantral follicles. In: Resumos da XX Reunião Anual da SBTE (Araxá, Brasil). p.265.

37 Misajon A., Hutchinson P., Lolatgis N., Trounson A.O. \& Almahbobi G. 1999. The mechanism of action of epidermal growth factor and transforming growth factor alpha on aromatase activity in granulosa cells from polycystic ovaries. Molecular Human Reproduction. 5: 96-103.

38 Monget P., Fabre S., Mulsant P., Lecerf F., Elsen J.M., Mazerbourg S., Pisselet C. \& Monniaux D. 2002. Regulation of ovarian folliculogenesis by IGF and BMP system in domestic animals. Domestic Animal Endocrinology. 23: $139-154$.

39 Monget P., Monniaux D. \& Durand P. 1989. Localization, characterization, and quantification of insulin-like growth factor-I-binding sites in the ewe ovary. Endocrinology. 125: 2486-2493.

40 Monniaux D., Huet C., Besnard N., Clément F., Bosc M., Pisselet C., Monget P. \& Mariana J.C. 1997. Follicular Growth and Ovarian Dynamics in Mammals. Journal of Reproduction and Fertility. 51: 3-23.

41 Nilsson E., Parrot J.A. \& Skinner M.K. 2001. Basic fibroblast growth factor induces primordial follicle development and initiates folliculogenesis. Molecular and Cellular Endocrinology. 175: 123-130.

42 O'Donnell J.R., Hill J.L. \& Gross D.J. 2004. Epidermal growth factor activates cytosolic [Ca $\left.{ }^{2+}\right]$ elevations and subsequent membrane permeabilization in mouse cumulus-oocyte complexes. Reproduction. 127: 207-220.

43 Ornitz D.M., Xu J., Colvin J.S., Mcewen D.G., Macarthur C.A., Coulier F., Gao G. \& Goldfarb M. 1996. Receptor Specificity of the Fibroblast Growth Factor Family. The Journal of Biological Chemistry. 271: 15292-15297.

44 Pan B., Sengoku K., Takuma N., Goishi K., Horikawa M., Tamate K. \& Ishikawa M. 2004. Differential expression of heparinbinding epidermal growth factor-like growth factor in the rat ovary. Molecular and Cellular Endocrinology. 214: 1-8.

45 Park J.Y., Su Y.Q., Ariga M., Law E., Jin S.L. \& Conti M. 2004. EGF-like growth factors as mediators of LH action in the ovulatory follicle. Science. 303: 682-684.

46 Parrott J.A. \& Skinner M.K. 2000. Kit ligand on ovarian stromal cells: effects on theca cell recruitment and steroid production. Molecular Reproduction and Development. 55: 55-64.

47 Parrott J.A., Vigne J.L., Chu B.Z. \& Skinner M.K. 1994. Mesenchymal-epithelial interactions in the ovarian follicle involve keratinocyte and hepatocyte growth factor production by thecal cells and their action on granulosa cells. Endocrinology. 135: 569-575.

48 Powers C.J., McLeskey S.W. \& Wellstein A. 2000. Fibroblast growth factors, their receptors and signaling. EndocrineRelated Cancer. 7: 165-197.

49 Qu J.P., Godin P.A., Nisolle M. \& Donnez J. 2000. Distribution of epidermal growth factor receptor expression of primordial follicles in human ovarian tissue before and after cryopreservation. Human Reproduction. 15: $302-310$.

50 Quennell J.H., Stanton J.A. \& Hurst P.R. 2004. Basic fibroblast growth factor expression in isolated small human ovarian follicles. Molecular Human Reproduction. 10: 623-628.

51 Rajarajan K., Rao B.S., Vagdevi R., Tamilmani G., Arunakumari G., Sreenu M., Amarnath D., Naik B.R. \& Rao V.H. 2006. Effect of various growth factors on the in vitro development of goat preantral follicles. Small Ruminant Research. 63 : 204-212. 
52 Reeka N., Berg F.D. \& Brucker C. 1998. Presence of transforming growth factor alpha and epidermal growth factor in human ovarian tissue and follicular fluid. Human Reproduction. 13: 2199-2205.

53 Riese D.J. \& Stern D.F. 1998. Specificity within the EGF family/ErbB receptor family signaling network. Bioassays. 20: 41-48.

54 Shimasaki S., Moore R.K., Otsuka F. \& Erickson G.F. 2004. The bone morphogenetic protein system in mammalian reproduction. Endocrine Reviews. 25: 72-101.

55 Silva J.R.V, van den Hurk R., van Tol H.T., Roelen B.A. \& Figueiredo J.R. 2006. The Kit ligand/c-Kit receptor system in goat ovaries: gene expression and protein localization. Zygote. 14: 317-328.

56 Silva J.R.V., Brito I.R., Leitão C.C.F., Silva A.W.B., Passos M.J., Fernandes L.A., Vasconcelos G.L. \& Figueiredo J.R. 2007. Expressão da proteína morfogenética óssea-6 (BMP-6) em folículos ovarianos caprinos. In: Resumos da XXI Reunião Anual da SBTE (Costa do Sauípe, BA, Brasil). p.1044.

57 Silva J.R.V., Brito I.R., Leitão C.C.F., Silva A.W.B., Passos M.J., Vasconcelos G.L., Saraiva M.V.A., Almeida A.P. \& Figueiredo J.R. 2008. Quantificação da proteína e do RNA mensageiro para o fator de crescimento semelhante à insulina1 (IGF-1) em folículos ovarianos caprinos. In: Resumos da XXII Reunião Anual da SBTE (Guarujá, SP, Brasil). p.466.

58 Silva J.R.V., Figueiredo J.R. \& van den Hurk R. 2009. Involvement of growth hormone (GH) and insulin-like growth factor (IGF) system in ovarian folliculogenesis. Theriogenology. 71: 1193-1208.

59 Silva J.R.V., Tharasanit T., Taverne M.A.M., van der Weijden G.C., Santos R.R., Figueiredo J.R. \& van den Hurk R. 2006. The activin-follistatin system and in vitro early follicle development in goats. Journal of Endocrinology. 189: 113125.

60 Silva J.R.V., van Den Hurk R., van Tol H.T.A., Roelen B.A.J. \& Figueiredo J.R. 2004. Expression of Growth Differentiation Factor 9 (GDF9), Bone Morphogenetic Protein 15 (BMP15) and BMP Receptors in the Ovaries of Goats. Molecular Reproduction and Development. 70: 11-19.

61 Silva J.R.V., van den Hurk R., van Tol H.T.A., Roelen B.A.J. \& Figueiredo J.R. 2004. Gene expression and protein localisation for activin-A, follistatin and activin receptors in goat ovaries. Journal of Endocrinology. 183: 405-415.

62 Silva R.V., van den Hurk R. \& Figueiredo J.R. 2006. Expression of mRNA and protein localization of epidermal growth factor and its receptor in goat ovaries. Zygote. 14: 107-117.

63 Silva R.V., van den Hurk R., Matos M.H.T., Santos R.R., Pessoa C., Moraes M.O. \& Figueiredo J.R. 2004. Influences of FSH and EGF on primordial follicles during in vitro culture of caprine ovarian cortical tissue. Theriogenology. 61: 16911704.

64 Singh B., Rutledge J.M. \& Armstrong D.T. 1995. Epidermal growth factor and its receptor gene expression and peptide localization in porcine ovarian follicles. Molecular Reproduction and Development. 40: 391-399.

65 Skinner M.K. \& Coffey R.J. 1988. Regulation of ovarian cell growth through the local production of transforming growth factor-alpha by theca cells. Endocrinology. 123: 2632-2638.

66 Souza C.J., Campbell B.K., Mcneilly A.S. \& Baird D.T. 2002. Effect of bone morphogenetic protein 2 (BMP2) on oestradiol and inhibin A production by sheep granulosa cells, and localization of BMP receptors in the ovary by immunohistochemistry. Reproduction. 123: 363-369.

67 Spicer L.J., Santiago C.A., Davidson T.R., Bridges T.S. \& Chamberlain C.S. 2005. Follicular fluid concentrations of free insulin-like growth factor (IGF)-I during follicular development in mares. Domestic Animal Endocrinology. 29: 573-581.

68 Tanwar P.S., O'Shea T. \& McFarlane J.R. 2008. In vivo evidence of role of bone morphogenetic protein-4 in the mouse ovary. Animal Reproduction Science. 106: 232-240.

69 Tilly J.L., Billig H., Kowalski K.I. \& Hsueh A.J. 1992. Epidermal growth factor and basic fibroblast growth factor suppress the spontaneous onset of apoptosis in cultured rat ovarian granulosa cells and follicles by a tyrosine kinase-dependent mechanism. Molecular Endocrinology. 6: 1942-1950.

70 Tisdall D.J., Fidler A.E., Smith P., Quirke L.D., Stent V.C., Heath D.A. \& McNatty K.P. 1999. Stem cell factor and c-kit gene expression and protein localization in the sheep ovary during fetal development. Journal of Reproduction and Fertility. 116: 277-291.

71 van den Hurk R. \& Zhao J. 2005. Formation of ovarian follicles and their growth, differentiation and maturation within ovarian follicles. Theriogenology. 63: 1717-1751.

72 van Wezel I.L., Umapathysivam K., Tilley W.D. \& Rodgers R.J. 1995. Immunohistochemical localization of basic fibroblast growth factor in bovine ovarian follicles. Molecular and Cellular Endocrinology. 115: 133-140. 
73 Vernon R.K. \& Spicer L.J. 1994. Effects of basic fibroblast growth factor and heparin on follicle-stimulating hormoneinduced steroidogenesis by bovine granulosa cells. Journal of Animal Science. 72: 2696-2702.

74 Wandji S.A., Srsen V., Voss A.K., Eppig J.J. \& Fortune J.E. 1996. Initiation in vitro of growth of bovine primordial follicles. Biology of Reproduction. 55: 942-948.

75 Welt C.K., Adams J.M., Sluss P.M. \& Hall J.E. 1999. Inhibin A and inhibin B responses to gonadotropin withdrawal depends on stage of follicle development. Journal of Clinical Endocrinology \& Metabolism. 84: 2163-2169.

76 Welt C.K. \& Schneyer A.L. 2001. Differential regulation of inhibin B and inhibin a by follicle-stimulating hormone and local growth factors in human granulosa cells from small antral follicles. Journal of Clinical Endocrinology \& Metabolism. 86: 330-336.

77 Wiater E. \& Vale W. 2003. Inhibin is an antagonist of bone morphogenetic protein signaling. The Journal of Biological Chemistry. 278: 7934-7941.

78 Yoshida H., Takakura N., Kataoka H., Kunisada T., Okamura H. \& Nishikawa S.I. 1997. Stepwise requirement of c-kit tyrosine kinase in mouse ovarian follicle development. Developmental Biology. 184: 122-137.

79 Zhou H. \& Zhang Y. 2005. Regulation of in vitro growth of preantral follicles by growth factors in goats. Domestic Animal Endocrinology. 28: 235-242.

80 Zhou J., Adesanya O.O., Vatzias G., Hammond J.M. \& Bondy C.A. 1996. Selective expression of insulin-like growth factor system components during porcine ovary follicular selection. Endocrinology. 137: 4893-4901. 